\title{
Oxybutynin topical gel in the treatment of overactive bladder
}

\author{
This article was published in the following Dove Press journal: \\ Open Access Journal of Urology \\ 15 June 2010 \\ Number of times this article has been viewed
}

\section{G Willy Davila \\ Department of Gynecology, Cleveland Clinic Florida, Weston, Florida, USA}

Correspondence: G Willy Davila

Cleveland Clinic Florida, 2950 Cleveland

Clinic Boulevard, Weston, FL 3333I, USA

Tel + I 9546595559

Fax + I 9546595560

Email davilag@ccf.org
Abstract: Overactive bladder (OAB), often accompanied by urinary incontinence, is most prevalent among the elderly, but also affects many middle-aged men and women in the US. OAB may severely impair quality of life, and its overall economic costs to society are substantial. Although antimuscarinic agents relieve OAB symptoms effectively, treatment persistence generally is low. This has been attributed in part to the occurrence of dry mouth and other anticholinergic adverse events. High plasma concentrations of $\mathrm{N}$-desethyloxybutynin (DEO), an active metabolite of oxybutynin, have been identified as the major cause of anticholinergic adverse effects associated with oral oxybutynin. Transdermal formulations of oxybutynin generate much lower DEO plasma concentrations compared with oral formulations. In a placebo-controlled US Phase III study in patients with OAB, the recently approved oxybutynin topical gel (OTG) was efficacious and well tolerated. Dry mouth occurred in $6.9 \%$ of patients treated with OTG and $2.8 \%$ of patients on placebo. Incidences of other anticholinergic events were low and similar for OTG and placebo. OTG rarely caused application site skin reactions. OTG provides significant benefits to patients with $\mathrm{OAB}$, particularly those who are sensitive to anticholinergic adverse effects.

Keywords: overactive bladder, oxybutynin topical gel, antimuscarinic, urinary urgency, incontinence

\section{Introduction}

Overactive bladder $(\mathrm{OAB})$ is a syndrome characterized by urinary urgency with or without incontinence and is usually accompanied by urinary frequency and nocturia. ${ }^{1}$ Results of the National Overactive BLadder Evaluation (NOBLE) program suggest that the prevalence of OAB in the US is similar for men (16\%) and women $(16.9 \%)$, but $\mathrm{OAB}$ with urge incontinence affects significantly more women $(7.6 \%)$ than men $(2.6 \%) .^{2}$ The prevalence of OAB increases with age in an essentially linear association from 25 to 75 years. ${ }^{2} \mathrm{OAB}$ with urge incontinence in women was shown to increase sharply during middle age; as a result, approximately $12 \%$ of women aged $45-54$ years are affected. ${ }^{2}$ A population-based survey conducted in Canada and 4 European countries estimated the overall prevalence of $\mathrm{OAB}$ at $11.8 \%{ }^{3}$

OAB can severely impair physical and mental well-being. Nocturia reduces quality of sleep, and OAB symptoms, particularly if accompanied by incontinence, may reduce work productivity and sexual activity, and limit mobility and social interactions. ${ }^{2-6}$ Results from several studies suggest that $\mathrm{OAB}$ with incontinence significantly increases the incidence and severity of depression. ${ }^{2,5}$ Incontinence has been associated with recurrent urinary tract infections in women ${ }^{2,7}$ and increased risk of falls and consequent 
fractures in elderly women. ${ }^{8}$ The costs of treating OAB-related urinary infections and injuries from falls in the US were estimated at $\$ 2$ billion in $2000 .{ }^{9}$ Total costs during the same year for diagnosis and treatment of $\mathrm{OAB}$, consequent care, and lost productivity were estimated at $\$ 12$ billion. ${ }^{10}$

Bladder filling status and micturition reflex are controlled by the parasympathetic nervous system. ${ }^{11}$ The cause of idiopathic OAB symptoms remains essentially unknown, ${ }^{12}$ and muscarinic acetylcholine receptor antagonists remain the only pharmacotherapy with a clinically proven mechanism for treating OAB.$^{13}$ It is generally believed that antimuscarinics ameliorate the symptoms of OAB by promoting bladder detrusor muscle relaxation during the storage phase as a result of $\mathrm{M} 3$ receptor antagonism. ${ }^{14}$ However, on the basis of animal studies, it has been suggested recently that antimuscarinics also modulate bladder afferent information, including urge sensation, from the bladder to the central nervous system through several mechanisms. ${ }^{15,16}$

\section{Evolution of oxybutynin in treatment of OAB}

Oxybutynin is a well established treatment for OAB and has been commercially available in the US since the 1970s. It is one of a growing number of antimuscarinic agents that have received a Grade A recommendation from the International Consultation on Incontinence for the treatment of OAB. ${ }^{17}$ Results of a recent meta-analysis of clinical studies of currently licensed antimuscarinics found no statistically significant differences in efficacy among these agents and no statistically significant association between antimuscarinic therapy and serious adverse events. ${ }^{18}$ However, antimuscarinics varied regarding their adverse effect profiles and effects on health-related quality of life (HRQoL) ${ }^{19}$ Anticholinergic adverse effects, particularly dry mouth, are common in patients receiving oral antimuscarinics ${ }^{18}$ and are a likely cause of low treatment persistence. ${ }^{19}$

Over the years, a number of formulations of oxybutynin have been developed, including various oral formulations and 2 transdermal formulations. The originally developed immediate-release oral formulation is associated with a high incidence of dry mouth and other anticholinergic adverse effects. ${ }^{20}$ Introduction of the extended-release oral formulation of oxybutynin significantly reduced the incidence of anticholinergic events ${ }^{21}$ and consequently improved medication adherence ${ }^{19}$ compared with immediate-release oral oxybutynin. However, the extended-release formulation is still associated with a relatively high incidence of dry mouth, which has exceeded $50 \%$ in some clinical studies. ${ }^{22}$
Pharmacokinetic evidence suggests that the anticholinergic adverse effects of oral oxybutynin are largely attributable to high plasma concentrations of $N$-desethyloxybutynin ( $N$-DEO), an active metabolite of oxybutynin. $N$-DEO is generated in large quantities in the liver and gut by first-pass metabolism of orally administered oxybutynin involving cytochrome P-450 (CYP-450). ${ }^{23,24}$ The plasma concentrations of $N$-DEO generated from immediate-release oxybutynin may be up to 10 times those of oxybutynin itself. ${ }^{25}$ The improved anticholinergic adverse event profile of extended-release oxybutynin compared with immediate-release oxybutynin is attributable to a reduction in the ratio of total $N$-DEO to oxybutynin plasma exposures. For the extended-release formulation, steady-state plasma exposure of $N$-DEO is approximately four times that of oxybutynin. ${ }^{26} N$-DEO and oxybutynin appear to have similar affinities for muscarinic M3 receptors, which represent the dominant receptor subtype in the salivary gland, ${ }^{27,28}$ and are believed to mediate bladder smooth muscle contraction during micturition. ${ }^{11}$

To avoid the first-pass hepatic and gastrointestinal metabolism of orally administered oxybutynin, transdermal formulations of oxybutynin have been developed. The first transdermal formulation (oxybutynin transdermal delivery system [TDS]) was a patch delivery system. In pharmacokinetic studies involving healthy volunteers, single-dose and steady-state plasma concentrations of $N$-DEO obtained with oxybutynin TDS were substantially lower than those obtained with oral formulations. ${ }^{26,29,30}$ The mean ratio of $N$-DEO to oxybutynin steady-state plasma exposures observed with oxybutynin TDS was 1.2 or 1.3 , depending on the study. ${ }^{26,30}$ Moreover, healthy subjects produced significantly more saliva if they received transdermal rather than extendedrelease oxybutynin. ${ }^{26}$ Subsequent Phase II and Phase III clinical studies in mostly female patients with OAB demonstrated that the efficacy of oxybutynin TDS is similar to that of immediate-release oxybutynin and extended-release tolterodine. ${ }^{31-33}$ In one of these studies, the incidence of dry mouth associated with oxybutynin TDS was similar to that associated with placebo. ${ }^{32}$ The excellent anticholinergic tolerability of oxybutynin TDS was also evident in a six-month, community-based, open-label study of almost 3000 patients, of whom only $2.6 \%$ experienced dry mouth. Consistent with this observation, oxybutynin TDS was found to improve HRQoL significantly. ${ }^{18,34}$

A drawback of oxybutynin TDS compared with oral formulations appears to be the propensity of the patch delivery system to cause application site skin reactions in some patients. In the community-based, open-label study 
of oxybutynin TDS, $14 \%$ of the mostly female patients reported application site reactions, including pruritus, erythema, and dermatitis. ${ }^{34}$ Application site pruritus also has been observed in patients using placebo patches $(6.1 \%$ in a placebo-controlled Phase III study). ${ }^{32}$ This raises questions concerning the precise cause of oxybutynin TDS-associated application site reactions. Skin occlusion and desquamation caused by the patch may be important contributing factors, suggesting that the incidence of application site reactions could be substantially reduced by using a different TDS. Following this rationale, a new gel-based TDS for oxybutynin has been developed. ${ }^{35-38}$ Oxybutynin topical gel (OTG) was specifically designed to improve the skin tolerability of transdermal delivery while maintaining its excellent anticholinergic tolerability profile. OTG ${ }^{39}$ was approved by the US Food and Drug Administration in January 2009.

\section{Oxybutynin topical gel Formulation and pharmacokinetics}

One dose of OTG consists of $1 \mathrm{~g}$ of a semisolid and colorless gel that contains oxybutynin $100 \mathrm{mg}(10 \% \mathrm{w} / \mathrm{w})$ and has a volume of less than a quarter of a tablespoon $(1.14 \mathrm{~mL})$. Each dose of OTG is packaged in a single sachet and should be applied once daily to the abdomen, upper arm/shoulder, or thigh. The application site location has only minor effects on the steady-state pharmacokinetics of OTG and therefore is not expected to have a clinically meaningful impact on the efficacy or tolerability of OTG. ${ }^{40}$ OTG is fragrance-free and leaves no residues or stains on the skin. The hydroalcoholic solvent ensures effective skin penetration and a short drying time after application. Hydroxypropyl cellulose is used as the gelling agent, and glycerin is present as an emollient.

Oxybutynin is a tertiary amine with a molecular weight of $357 \mathrm{Da}$. Depending on the $\mathrm{pH}$, it can exist in charged form (oxybutynin chloride) or as a free, uncharged base (Figure 1). As a free base, oxybutynin is lipophilic and is easily absorbed by the skin. OTG contains sodium hydroxide, which maintains the $\mathrm{pH}$ of the gel at $\mathrm{pH} 6$ (ie, within the range of physiologic skin $\mathrm{pH}$ ). Because oxybutynin exists mostly as a free base at $\mathrm{pH} 6$, the OTG formulation supports both

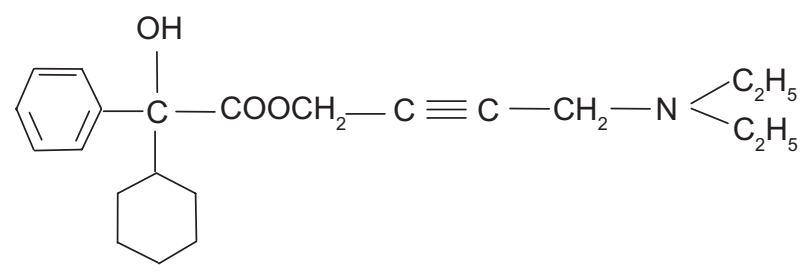

Figure I Structural formula of oxybutynin. optimal skin tolerability and effective drug absorption. The OTG formulation does not include a permeation enhancer.

To enter the systemic circulation, oxybutynin must penetrate the stratum corneum and epidermis and enter the capillary system located in the dermis. Unpublished pharmacokinetic data suggest that the release of oxybutynin into the systemic circulation occurs gradually. A sufficiently slow release of oxybutynin into the circulation is an essential prerequisite for the once-daily dosing schedule. It has been shown previously that the stratum corneum and the dermis may function as storage depots during the delivery of topically applied steroids to the systemic circulation. ${ }^{41}$ It is conceivable that the skin assumes a similar reservoir function during the delivery of topically applied oxybutynin.

During development of the OTG formulation, it was important to find a formulation strength (ie, oxybutynin concentration in the gel) that would make delivery of the drug both efficient and convenient. A 10\% (w/w) OTG formulation was found to meet these criteria best.

Comparison of the pharmacokinetic profiles of oxybutynin TDS and OTG in healthy volunteers revealed that both formulations resulted in similar plasma exposures of oxybutynin and $N$-DEO. After administration of single doses to 20 subjects in a cross-over study, plasma exposures to oxybutynin were $322 \mathrm{ng} \cdot \mathrm{h} / \mathrm{mL}$ for OTG and $312 \mathrm{ng} \cdot \mathrm{h} / \mathrm{mL}$ for oxybutynin TDS; the ratio of $N$-DEO to oxybutynin exposures was 0.8 for OTG and 1.1 for oxybutynin TDS. Mathematical simulations using nonlinear regression models predicted that the two formulations would have very similar steady-state kinetics. This prediction was subsequently borne out by the results of a multiple dosing study in 22 healthy adults. ${ }^{42}$ Subjects received 18 daily applications of OTG followed by five applications of oxybutynin TDS every 3.5-4.0 days, or vice versa. The two treatment periods were separated by a 14-day washout period, and the order of treatment was assigned randomly. The 4-day pharmacokinetic profile of oxybutynin was very similar for OTG and oxybutynin TDS (Figure 2). Total plasma exposure to oxybutynin was $322 \mathrm{ng} \cdot \mathrm{h} / \mathrm{mL}$ for OTG and $312 \mathrm{ng} \cdot \mathrm{h} / \mathrm{mL}$ for oxybutynin TDS; the ratio of $N$-DEO to oxybutynin exposure was 0.8 for OTG and 1.1 for oxybutynin TDS (Table 1). The lower ratio for OTG was almost exclusively attributable to a lower plasma exposure to $N$-DEO for gel versus patch delivery (Table 1, Figure 2).

Because oxybutynin is easily absorbed by the skin, the possibility of transference of oxybutynin to an untreated subject through skin-to-skin contact with a treated patient has been investigated. Healthy couples, each consisting of an untreated and a treated subject, engaged in vigorous 
A

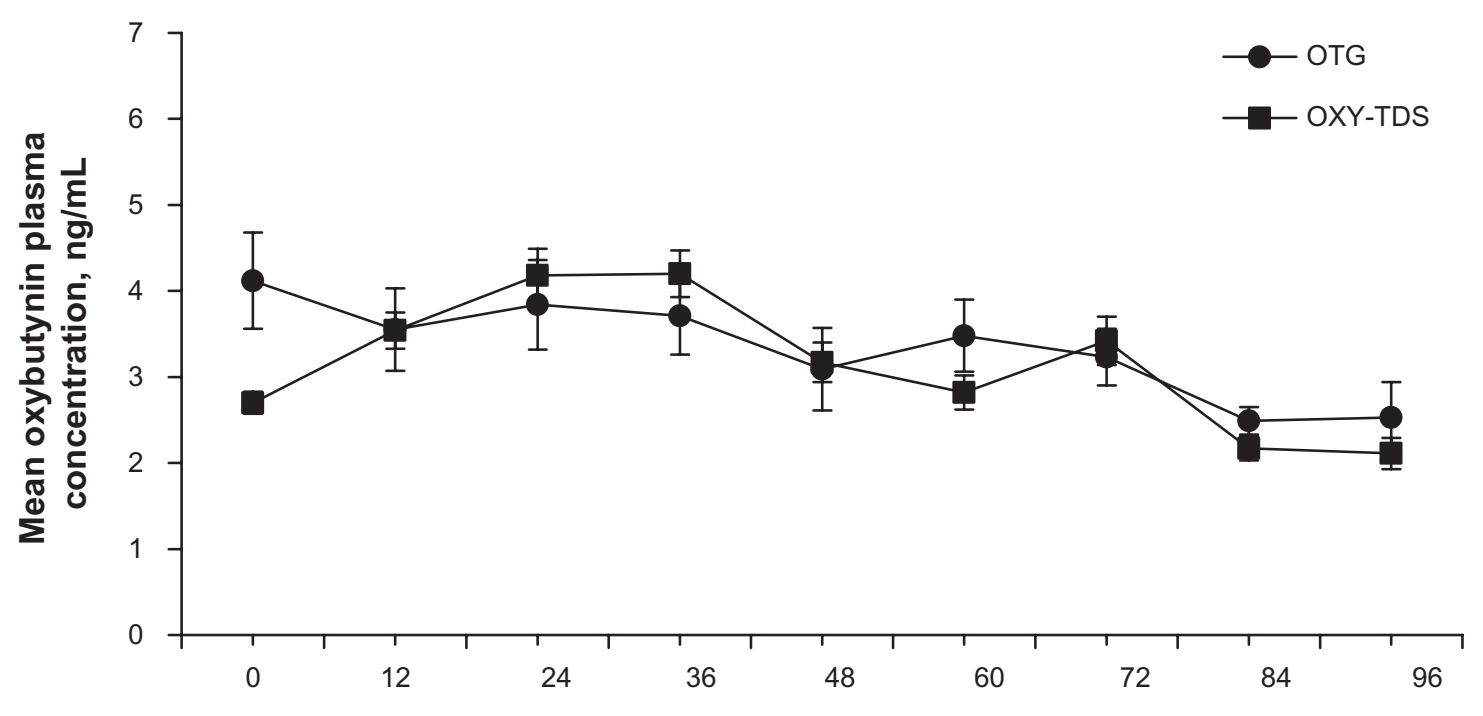

Time during last 4 days of dosing, hours

$\mathbf{B}$

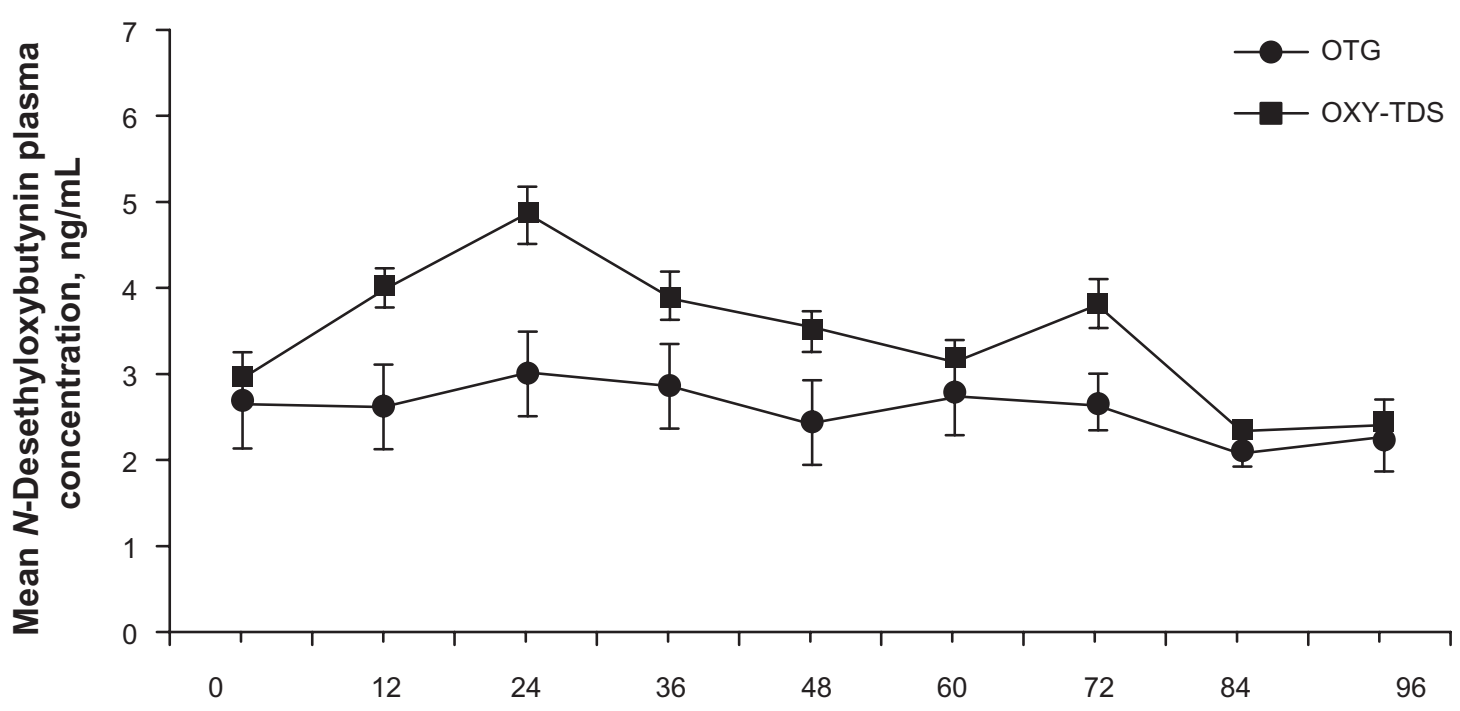

Time during last 4 days of dosing, hours

Figure 2 Mean oxybutynin (A) and N-DEO plasma concentrations in healthy adults treated with 10\% OTG or OXY-TDS. Error bars indicate standard errors of the mean. Adapted with permission from Caramelli KE, Staskin DR, Volinn W. Steady-state pharmacokinetics of an investigational oxybutynin topical gel in comparison with oxybutynin transdermal system. J Urol. 2008; 179(2):5।3-5I4. Copyright (C) 2008 Elsevier. ${ }^{42}$

Abbreviations: OTG, oxybutynin topical gel; OXY-TDS, oxybutynin transdermal system; N-DEO, N-desethyloxybutynin.

15-minute bare skin contact at the OTG application site one hour after application. Transference appeared to vary widely among couples but was generally small. Exposure due to transference was undetectable in most untreated subjects if the application site was covered with clothing during contact. ${ }^{43}$ Given the rigorous but highly artificial experimental conditions of the study, transference under real-life circumstances, if it occurs at all, can be expected to be of little clinical significance. However, for a caregiver who routinely assists a patient in applying OTG, it may be 
Table I Steady-state pharmacokinetics of OTG and OXY-TDS

\begin{tabular}{lll}
\hline Parameter, mean (SD) & $\begin{array}{l}\text { OTG } \\
\mathbf{( N = 2 0 )}\end{array}$ & $\begin{array}{l}\text { OXY-TDS } \\
\mathbf{( N = 2 0 )}\end{array}$ \\
\hline Oxybutynin AUC[0-96 h], ng.h/mL & $321.7(I 12.3)$ & $312.5(67.6)$ \\
N-DEO AUC[0-96 h], ng.h/mL & $246.4(97.0)$ & $338.0(116.9)$ \\
Ratio, N-DEO/oxybutynin[0-96 h] & $0.77(0.19)$ & $1.07(0.22)$ \\
\hline
\end{tabular}

Abbreviations: AUC, area under the plasma concentration-time curve; N-DEO, $\mathrm{N}$-desethyloxybutynin; OTG, oxybutynin topical gel; OXY-TDS, oxybutynin transdermal system; SD, standard deviation.

advisable to avoid direct skin-to-skin contact with the application site (shortly after application) if the caregiver is sensitive to or contraindicated for anticholinergic agents.

\section{Clinical efficacy}

The results of a double-blind, randomized, placebo-controlled Phase III study of OTG in patients with OAB have been published recently. ${ }^{44}$ The 12 -week study was conducted at 76 clinical centers in the US and enrolled a total of 789 patients with urge or mixed urinary incontinence. Most of the patients $(89.2 \%)$ were women, and slightly more than a third of the study participants were 65 years or older. Approximately a quarter of all patients had previously taken OAB medications. Baseline values indicated that a substantial proportion of patients had severe OAB symptoms. For both treatment groups, the mean number of daily urinary incontinence episodes at baseline was 5.4 and the mean number of daily nocturia events at baseline was 2.5; mean daily frequency at baseline was 12.4 for patients assigned to OTG and 12.2 for those assigned to placebo. Patients receiving OTG experienced a greater reduction in the numbers of daily incontinence episodes (mean decrease -3.0 versus -2.5 ; $P<0.0001$, Figure 3) and daily frequency episodes (mean decrease -2.7 versus $-2.0 ; P=0.0017$ ) than those receiving placebo, but a significantly greater decrease in nocturia episodes in the OTG group was observed only in patients younger than 65 years (mean decrease -0.91 versus -0.72 ; $P=0.0363$ ). Voided volume at baseline was greater than 160 $\mathrm{mL}$ in most patients and on average increased by $21.0 \mathrm{~mL}$ in those treated with OTG (placebo $3.8 \mathrm{~mL} ; P=0.0018$ ). At study end, $28 \%$ of the patients treated with OTG and $17 \%$ of those who received placebo had achieved complete continence.

\section{Efficacy in female patients}

The efficacy of OTG specifically in women with OAB was assessed in a subgroup analysis of the Phase III study population. ${ }^{45}$ Each treatment group included 352 female patients. Mean age was 59 years. Baseline demographic and urinary symptom values for the female subgroup were very similar to those for the total study population. Female

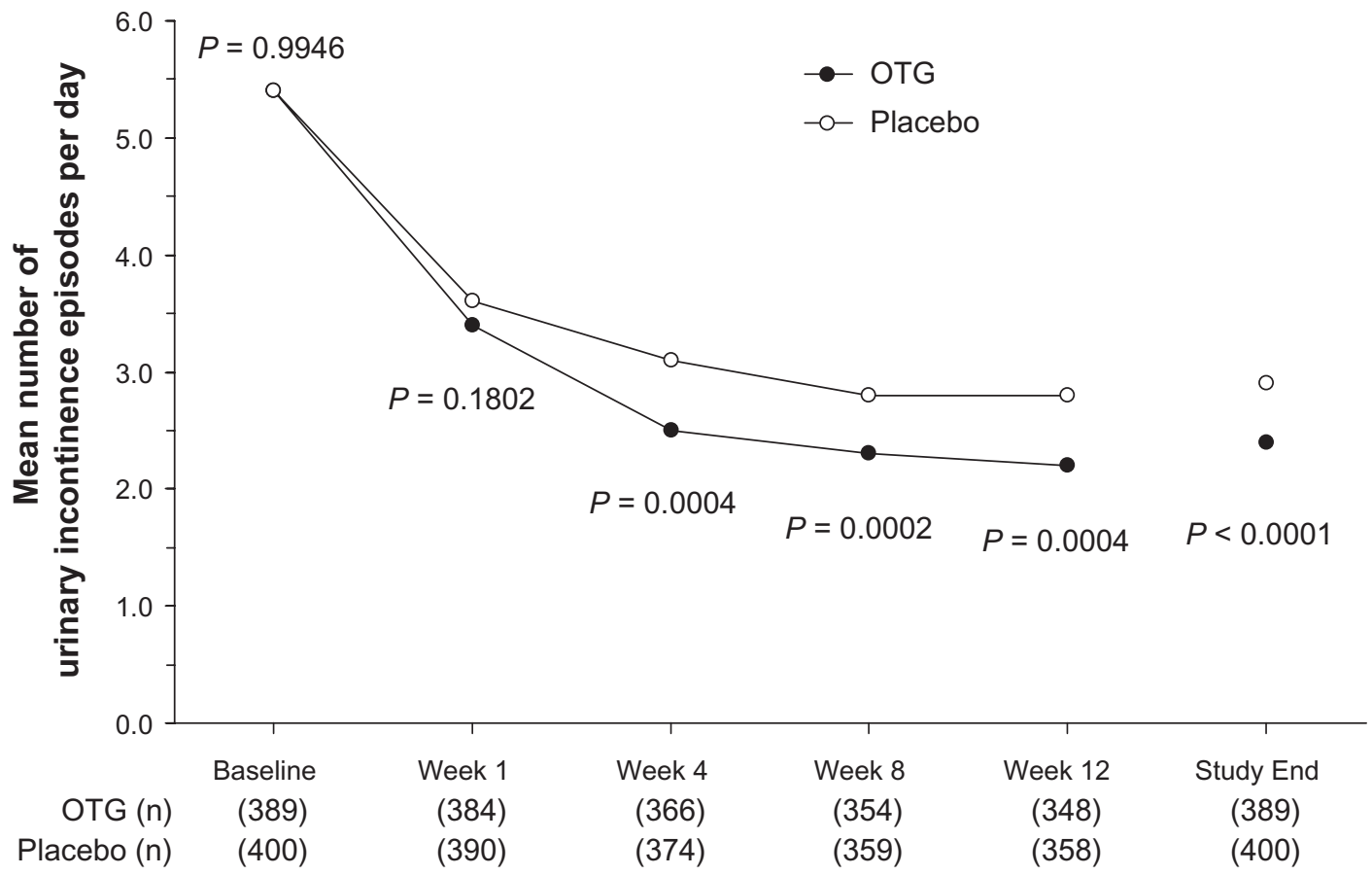

Figure 3 Mean change from baseline in daily urinary incontinence episodes. $P$ values were derived from analysis of variance of baseline data and from analysis of covariance of post-baseline data. Last observations were carried forward for study end only. Reprinted with permission from Staskin DR, Dmochowski RR, Sand PK, et al. Efficacy and safety of oxybutynin chloride topical gel for overactive bladder: A randomized, double-blind, placebo controlled, multicenter study. J Urol. 2009; I8I (4): I764-1772. Copyright (C) 2008 Elsevier. ${ }^{44}$

Abbreviation: OTG, oxybutynin topical gel. 
patients who received OTG versus placebo experienced significantly greater improvement $(P<0.0001)$ in daily incontinence episodes (mean decrease -3.0 versus -2.5 ), daily frequency (mean decrease -2.8 versus -2.0 ), and voided volume (mean increase $22.7 \mathrm{~mL}$ versus $4.0 \mathrm{~mL}$ ). At study end, $27.0 \%$ of women treated with OTG compared with $15.6 \%$ of those receiving placebo had achieved complete continence. ${ }^{45}$

\section{Effects on quality of life}

During the Phase III study, HRQoL was evaluated with the five-item Incontinence Impact Questionnaire (IIQ) and the 10-item King's Health Questionnaire (KHQ). OTG versus placebo was associated with significant improvement in all IIQ domains (ie, emotional health, social relationships, travel, and physical activity; $P<0.01) .{ }^{46}$ Moreover, significant HRQoL improvements with OTG versus placebo were observed in the KHQ domains of incontinence impact, symptom severity, role limitations, personal relationships, severity (coping) measures, and sleep/energy $(P<0.05)$.

\section{Safety and tolerability Overall tolerability and adverse anticholinergic effects}

No treatment-related serious adverse events were observed during the Phase III study of OTG. ${ }^{44}$ The overall discontinuation rate because of adverse events was not substantially higher with OTG (4.9\%) than with placebo (3.3\%, Table 2$)$. The most commonly reported adverse event was dry mouth.
The incidence of dry mouth in the OTG group $(6.9 \%)$ was significantly higher than in the placebo group $(2.8 \%$, $P=0.0060$, Table 2 ), but substantially smaller than the incidences of dry mouth reported in comparable studies of oral oxybutynin. ${ }^{22}$ No treatment-related anticholinergic event other than dry mouth occurred in more than $2 \%$ of patients treated with OTG, including constipation (1.3\%), dizziness $(1.5 \%)$, nausea $(0.3 \%)$, dry eye $(0.5 \%)$, dysuria $(0.3 \%)$, and somnolence $(0.3 \%) .{ }^{44}$ Dry mouth was the only anticholinergic event with a statistically significant difference in incidence between OTG and placebo (Table 2). ${ }^{44}$

\section{Effects on skin}

The skin tolerability of OTG was tested extensively in preclinical and clinical studies. OTG is unlikely to cause phototoxicity because the degree of light absorption by the gel at wavelengths of 290-700 nm is insignificant. A study in albino guinea pigs further suggested that OTG does not elicit dermal reactions or delayed contact sensitization. These findings were confirmed by two dermatologic studies of OTG in healthy subjects. Using the Berger and Bowman scale ${ }^{47}$ to score cumulative skin irritation in 41 subjects, mean scores obtained with OTG and placebo were 35 and 24, respectively. Both scores were substantially less than 50 , which is the lowest score considered as evidence of cumulative irritation. In the second study, 201 subjects received nine OTG applications over a period of 3 weeks and a final challenge application after a rest period of 2 weeks. During the following 72 hours, the frequency and severity of skin reactions were assessed. The vast majority

Table 2 AEs reported during double-blind study treatment

\begin{tabular}{|c|c|c|c|}
\hline No. of patients (\%) & $\begin{array}{l}\text { OTG } \\
(n=389)\end{array}$ & $\begin{array}{l}\text { Placebo } \\
(n=400)\end{array}$ & $P$ value \\
\hline$\geq \mathrm{IAE}$ & $221(56.8)$ & $193(48.3)$ & $0.0160^{+}$ \\
\hline$\geq \mathrm{I}$ treatment-related $\mathrm{AE}$ & $73(18.8)$ & $45(11.3)$ & $0.003 \mathrm{I}^{+}$ \\
\hline$\geq I$ serious $A E$ & $7(1.8)$ & $10(2.5)$ & $0.498 \mathrm{I}^{+}$ \\
\hline$\geq I$ treatment-related serious $\mathrm{AE}$ & 0 & 0 & \\
\hline AE resulting in study withdrawal & $19(4.9)$ & $13(3.3)$ & $0.2446^{\dagger}$ \\
\hline \multicolumn{4}{|c|}{$\begin{array}{l}\text { Treatment-related AEs reported by } \geq 1 \% \text { of } \\
\text { patients in OTG group }\end{array}$} \\
\hline Dry mouth & $27(6.9)$ & II (2.8) & $0.0060^{+}$ \\
\hline Application site pruritus & $8(2.1)$ & $3(0.8)$ & $0.1176^{\dagger}$ \\
\hline Application site dermatitis & $7(1.8)$ & I $(0.3)$ & $0.0358^{\ddagger}$ \\
\hline Headache & $6(1.5)$ & II (2.8) & $0.2428^{\dagger}$ \\
\hline Constipation & $5(1.3)$ & $4(1.0)$ & $0.7494^{\ddagger}$ \\
\hline Dizziness & $6(1.5)$ & $2(0.5)$ & $0.1719^{\ddagger}$ \\
\hline Pruritus & $5(1.3)$ & $5(1.3)$ & $1.0000^{\ddagger}$ \\
\hline
\end{tabular}

Notes: ${ }^{\dagger}$ Chi-square test. ${ }^{\ddagger}$ Fisher's exact test. Reprinted with permission from Staskin DR, Dmochowski RR, Sand PK, et al. Efficacy and safety of oxybutynin chloride topical gel for overactive bladder: A randomized, double-blind, placebo controlled, multicenter study. J Urol. 2009; I8I (4): I764-I772. Copyright (C) 2008 Elsevier. ${ }^{44}$

Abbreviations: AE, adverse event; OTG, oxybutynin chloride topical gel. 
of subjects receiving OTG (93\%) or placebo $(94.5 \%)$ had no skin reactions.

Excellent skin tolerability of OTG was also observed during the Phase III trial. ${ }^{44}$ Application site skin reactions were reported by $5.4 \%$ of patients who received OTG and by $1 \%$ of those who received placebo. Eight of 389 patients $(2.1 \%)$ treated with OTG and 3 of 400 patients $(0.8 \%)$ receiving placebo reported application site pruritus as an adverse event (Table 2). The incidence of application site erythema was similar among patients treated with OTG (1.3\% per visit) and those who received placebo ( $0.9 \%$ per visit). At study end, inspection of application sites by the investigator revealed no erythema in $97.4 \%$ and $98.7 \%$ of patients receiving OTG and placebo, respectively. ${ }^{44}$ Among the few patients receiving OTG who had application site erythema, none had severe symptoms, $3(0.8 \%$ of all patients receiving OTG) had moderate symptoms, and 7 (1.8\%) had mild symptoms. Three patients $(0.8 \%)$ in the OTG group and 1 patient $(0.3 \%)$ in the placebo group discontinued treatment because of application site reactions (reported as adverse events). ${ }^{44}$

\section{Conclusion}

OTG is a new transdermal formulation of oxybutynin that was specifically designed to minimize anticholinergic effects and application site skin reactions. Available clinical data show that OTG is efficacious in patients with urge and mixed urinary incontinence and is associated with low incidences of anticholinergic adverse events. OTG appears to have better skin tolerability than oxybutynin TDS, the previously developed transdermal patch formulation of oxybutynin. OTG has rarely caused application site skin reactions, and those that have occurred were mostly mild forms of pruritus and dermatitis. The excellent tolerability of OTG and its efficacy in OAB symptom improvement are most likely responsible for the significant improvements in HRQoL that were seen during treatment. These attributes, together with its convenient once-daily dosing schedule, make OTG a valuable new option for the treatment of $\mathrm{OAB}$.

\section{Acknowledgments}

Editorial assistance funded by Watson Pharma Inc was provided by Scientific Connexions, Newtown, Pennsylvania, USA.

\section{Disclosure}

The author is a speaker and consultant for Watson Pharmaceuticals.

\section{References}

1. Abrams P, Cardozo L, Fall M, et al. The standardisation of terminology in lower urinary tract function: Report from the standardisation subcommittee of the International Continence Society. Urology. 2003; 61(1):37-49.

2. Stewart WF, Van Rooyen JB, Cundiff GW, et al. Prevalence and burden of overactive bladder in the United States. World J Urol. 2003; 20(6):327-336.

3. Irwin DE, Milsom I, Hunskaar S, et al. Population-based survey of urinary incontinence, overactive bladder, and other lower urinary tract symptoms in five countries: results of the EPIC study. Eur Urol. 2006; 50(6):1306-1314.

4. Coyne KS, Payne C, Bhattacharyya SK, et al. The impact of urinary urgency and frequency on health-related quality of life in overactive bladder: Results from a national community survey. Value Health. 2004; 7(4):455-463.

5. Coyne KS, Sexton CC, Irwin DE, Kopp ZS, Kelleher CJ, Milsom I. The impact of overactive bladder, incontinence and other lower urinary tract symptoms on quality of life, work productivity, sexuality and emotional well-being in men and women: Results from the EPIC study. BJU Int. 2008;101(11):1388-1395.

6. Sexton CC, Coyne KS, Vats V, Kopp ZS, Irwin DE, Wagner TH. Impact of overactive bladder on work productivity in the United States: Results from EpiLUTS. Am J Manag Care. 2009;15 Suppl 4:S98-S107.

7. Stamm WE, Raz R. Factors contributing to susceptibility of postmenopausal women to recurrent urinary tract infections. Clin Infect Dis. 1999;28(4):723-725.

8. Brown JS, Vittinghoff E, Wyman JF, et al. Urinary incontinence: Does it increase risk for falls and fractures? Study of Osteoporotic Fractures Research Group. J Am Geriatr Soc. 2000;48(7):721-725.

9. Wagner TH, Hu TW, Bentkover J, et al. Health-related consequences of overactive bladder. Am J Manag Care. 2002;8 Suppl 19:S598-S607.

10. Hu TW, Wagner TH. Economic considerations in overactive bladder. Am J Manag Care. 2000;6 Suppl 11:S591-S598.

11. Abrams P, Andersson KE. Muscarinic receptor antagonists for overactive bladder. BJU Int. 2007;100(5):987-1006.

12. Gillespie JI, van Koeveringe GA, de Wachter SG, de Vente J. On the origins of the sensory output from the bladder: The concept of afferent noise. BJU Int. 2009;103(10):1324-1333.

13. Thomas L, Culley EJ. Overactive bladder disease: The urge for better therapies. J Manag Care Pharm. 2008;14(4):381-386.

14. Andersson KE, Yoshida M. Antimuscarinics and the overactive detrusor - which is the main mechanism of action? Eur Urol. 2003; 43(1):1-5.

15. Masuda H, Kim YT, Tyagi S, Chancellor MB, de Miguel F, Yoshimura N. Local effects of antimuscarinics. Urol Clin North Am. 2006;33(4):511-8, ix-X.

16. Hedlund P, Streng T, Lee T, Andersson KE. Effects of tolterodine on afferent neurotransmission in normal and resiniferatoxin treated conscious rats. J Urol. 2007;178(1):326-331.

17. Andersson KE, Appell R, Cardozo L, et al. Pharmacological treatment of urinary incontinence. In: Abrams P, Cardozo L, Khoury S, Wein A, editors. Third International Consultation on Incontinence. 2005:811-54. Available from: http://www.icsoffice.org/ASPNET_Membership/Membership/ Publications/ICI_3/v2.pdf/chap14 Accessed Aug 12, 2009.

18. Chapple CR, Khullar V, Gabriel Z, Muston D, Bitoun CE, Weinstein D. The effects of antimuscarinic treatments in overactive bladder: An update of a systematic review and meta-analysis. Eur Urol. 2008;54(3):543-562.

19. D’Souza AO, Smith MJ, Miller LA, Doyle J, Ariely R. Persistence, adherence, and switch rates among extended-release and immediaterelease overactive bladder medications in a regional managed care plan. J Manag Care Pharm. 2008;14(3):291-301.

20. Staskin DR, Macdiarmid SA. Using anticholinergics to treat overactive bladder: The issue of treatment tolerability. Am J Med. 2006;119 (3 Suppl 1):9-15. 
21. Anderson RU, Mobley D, Blank B, Saltzstein D, Susset J, Brown JS. Once daily controlled versus immediate release oxybutynin chloride for urge urinary incontinence. OROS Oxybutynin Study Group. J Urol. 1999;161(6):1809-1812.

22. Appell RA. Pharmacotherapy for overactive bladder: An evidence-based approach to selecting an antimuscarinic agent. Drugs. 2006;66(10): 1361-1370.

23. Starkman JS, Dmochowski RR. Management of overactive bladder with transdermal oxybutynin. Rev Urol. 2006;8(3):93-103.

24. Davila GW. Transdermal oxybutynin: A new treatment for overactive bladder. Expert Opin Pharmacother. 2003;4(12):2315-2324.

25. Hughes KM, Lang JC, Lazare R, et al. Measurement of oxybutynin and its $\mathrm{N}$-desethyl metabolite in plasma, and its application to pharmacokinetic studies in young, elderly and frail elderly volunteers. Xenobiotica. 1992;22(7):859-869.

26. Appell RA, Chancellor MB, Zobrist RH, Thomas H, Sanders SW. Pharmacokinetics, metabolism, and saliva output during transdermal and extended-release oral oxybutynin administration in healthy subjects. Mayo Clin Proc. 2003;78(6):696-702.

27. Waldeck K, Larsson B, Andersson KE. Comparison of oxybutynin and its active metabolite, N-desethyl-oxybutynin, in the human detrusor and parotid gland. J Urol. 1997;157(3):1093-1097.

28. Oki T, Kawashima A, Uchida M, Yamada S. In vivo demonstration of muscarinic receptor binding activity of N-desethyl-oxybutynin, active metabolite of oxybutynin. Life Sci. 2005;76(21):2445-2456.

29. Zobrist RH, Schmid B, Feick A, Quan D, Sanders SW. Pharmacokinetics of the R- and S-enantiomers of oxybutynin and N-desethyloxybutynin following oral and transdermal administration of the racemate in healthy volunteers. Pharm Res. 2001;18(7):1029-1034.

30. Zobrist RH, Quan D, Thomas HM, Stanworth S, Sanders SW. Pharmacokinetics and metabolism of transdermal oxybutynin: In vitro and in vivo performance of a novel delivery system. Pharm Res. 2003; 20(1):103-109.

31. Davila GW, Daugherty CA, Sanders SW. A short-term, multicenter, randomized double-blind dose titration study of the efficacy and anticholinergic side effects of transdermal compared to immediate release oral oxybutynin treatment of patients with urge urinary incontinence. J Urol. 2001;166(1):140-145.

32. Dmochowski RR, Davila GW, Zinner NR, et al. Efficacy and safety of transdermal oxybutynin in patients with urge and mixed urinary incontinence. J Urol. 2002;168(2):580-586.

33. Dmochowski RR, Sand PK, Zinner NR, Gittelman MC, Davila GW, Sanders SW. Comparative efficacy and safety of transdermal oxybutynin and oral tolterodine versus placebo in previously treated patients with urge and mixed urinary incontinence. Urology. 2003;62(2):237-242.

34. Sand P, Zinner N, Newman D, et al. Oxybutynin transdermal system improves the quality of life in adults with overactive bladder: A multicentre, community-based, randomized study. BJU Int. 2007; 99(4):836-844.
35. Chapple CR. Urinary incontinence: Oxybutynin topical gel for overactive bladder. Nat Rev Urol. 2009;6(7):351-352.

36. Staskin DR, Robinson D. Oxybutynin chloride topical gel: A new formulation of an established antimuscarinic therapy for overactive bladder. Expert Opin Pharmacother. 2009;10(18):3103-3111.

37. Sand PK. The evolution of transdermal therapy for overactive bladder. Curr Urol Rep. 2009;10(5):338-341.

38. MacDiarmid SA. The evolution of transdermal/topical overactive bladder therapy and its benefit over oral therapy. Rev Urol. 2009;2(2): 116-121.

39. Gelnique ${ }^{\circledR}$ (oxybutynin chloride) $10 \%$ gel [Prescribing information]. Corona, CA: Watson Pharmaceuticals, Inc.; 2009.

40. Caramelli KE, Thomas H, Stanworth S, Hoel G. Steady-state bioavailability of oxybutynin topical gel at 3 different application sites. Presented at: Annual Senior Care Pharmacy Meeting of the American Society of Consultant Pharmacists; November 19-22, 2008; New Orleans, Louisiana.

41. Roberts MS, Cross SE, Anissimov YG. Factors affecting the formation of a skin reservoir for topically applied solutes. Skin Pharmacol Physiol. 2004;17(1):3-16.

42. Caramelli KE, Staskin DR, Volinn W. Steady-state pharmacokinetics of an investigational oxybutynin topical gel in comparison with oxybutynin transdermal system. J Urol. 2008;179(2):513-514.

43. Caramelli KE, Stanworth S, Volinn W, Hoel G. Pharmacokinetics of oxybutynin topical gel: Effects of showering, sunscreen application, and person-to-person transference. Presented at: Annual Meeting of the American College of Clinical Pharmacy; October 19-22, 2008; Louisville, Kentucky.

44. Staskin DR, Dmochowski RR, Sand PK, et al. Efficacy and safety of oxybutynin chloride topical gel for overactive bladder: A randomized, double-blind, placebo controlled, multicenter study. J Urol. 2009; 181(4):1764-1772.

45. Dmochowski RR, Staskin DR, Macdiarmid SA, Caramelli KE, Thomas H, Hoel G. Efficacy and safety of oxybutynin chloride topical gel in women with overactive bladder: A randomized, placebocontrolled, double-blind study. J Urol. 2009;181(4):589.

46. Newman DK, Sand PK, Caramelli KE, Thomas H, Hoel G. Quality of life in a randomized, double-blind, placebo-controlled study of oxybutynin chloride topical gel treatment of patients with overactive bladder. Presented at: International Society for Pharmacoeconomics and Outcomes Research 14th Annual International Meeting; May 16-20, 2009; Orlando, Florida.

47. Berger RS, Bowman JP. A reappraisal of the 21-day cumulative irritation test in man. J Toxicol Cutaneous Ocul Toxicol. 1982;1(2):109-115.

Open Access Journal of Urology

\section{Publish your work in this journal}

The Open Access Journal of Urology is an international, peer-reviewed, open access journal publishing original research, reports, editorials, reviews and commentaries on all aspects of adult and pediatric urology in the clinic and laboratory including the following topics: Pathology, pathophysiology of urological disease; Investigation and treatment of

\section{Dovepress}

urological disease; Pharmacology of drugs used for the treatment of urological disease. The manuscript management system is completely online and includes a very quick and fair peer-review system, which is all easy to use. Visit http://www.dovepress.com/testimonials.php to read real quotes from published authors. 